\title{
Role of unsaturated soil mechanics in geotechnical engineering
}

\author{
Harianto Rahardjo ${ }^{*}$ Y Yongmin Kim and Alfrendo Satyanaga
}

${ }^{*}$ Correspondence:

chrahardjo@ntu.edu.sg

School of Civil

and Environmental

Engineering, Nanyang

Technological University,

50 Nanyang Avenue,

Singapore 639798, Singapore

\begin{abstract}
The understanding of unsaturated soil mechanics principles is of interest to a wide spectrum of geotechnical problems associated with soils above water table and compacted soils. This paper describes the stress state variables and constitutive equations based on the unsaturated soil mechanics principles. In addition, the basic concepts for characterization of unsaturated soils and measurements of matric suction (or negative pore-water pressures) are also explained. The application of unsaturated soil mechanics theories is illustrated through the use of capillary barrier system for minimizing rain infiltration into residual soil slopes.
\end{abstract}

Keywords: Unsaturated soil, Stress state variables, Constitutive equations, Soil-water characteristic curve, Numerical analysis

\section{Introduction}

Significant changes in climatic conditions in past decades are affected mostly by the increase in global temperature. Many countries experienced longer days of rainfall with higher intensities. Despite numerous debates about the existence of global warming, over $97 \%$ of climatologists reached an agreement that the changes in global climatic conditions are affected mainly by human activities [9]. A study on one aspect of climate change by Kim et al. [24], Rahardjo et al. [46] and Strauch et al. [51] indicated that climate change resulted in higher rainfall intensity with lesser frequency of rainy days. In addition, more water vapour is retained in the atmosphere due to the increase in average air temperature, which causes an exponential increase in the water vapour carrying capacity of the air [37].

Significant amount of rainfalls attributed to the changes in global climatic conditions may result in more frequent of rainfall-induced slope failures which affect properties and human lives as studied by Ciabatta et al. [8]. Rahardjo et al. [45] carried out research works on residual soil slopes. They observed that high and steep residual soil slopes can stand safely during dry periods. These slopes only failed during rainy periods. This fact is associated with the presence of an additional shear strength within the unsaturated zone [13] above the groundwater table.in residual soil slope. Hence, the slope is stable with a high factor of safety during dry periods (Fig. 1). However, the infiltration of rainwater during rainfall affects the negative pore-water pressure, resulting in a decrease in the additional shear strength within the unsaturated zone. As a result, the slope is more

(c) The Author(s) 2019. This article is distributed under the terms of the Creative Commons Attribution 4.0 International License (http://creativecommons.org/licenses/by/4.0/), which permits unrestricted use, distribution, and reproduction in any medium, provided you give appropriate credit to the original author(s) and the source, provide a link to the Creative Commons license, and indicate if changes were made. 


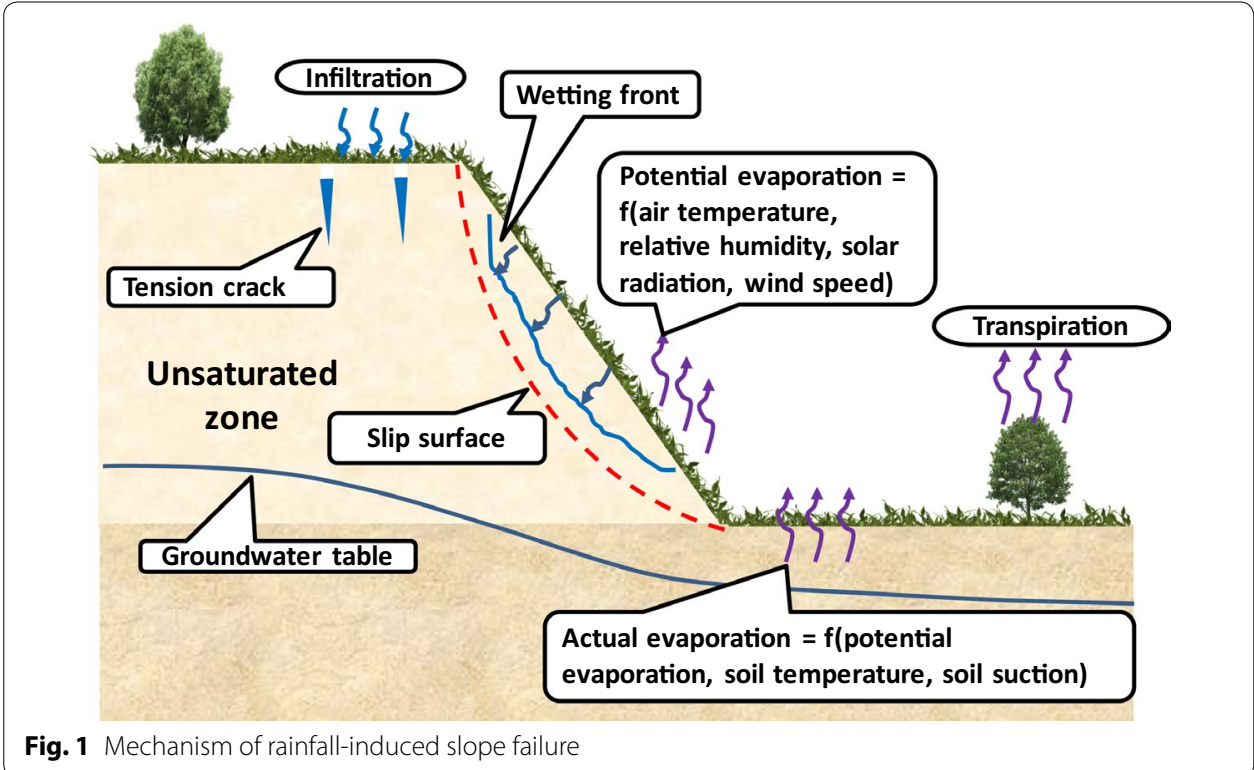

susceptible to failure during rainy periods [22, 38, 39, 42]. In other words, the instability of slopes during rainfall is commonly encountered in unsaturated soils, especially in tropical areas with frequently severe rainfall events $[6,44,54]$.

The magnitude of rainwater infiltration and the variations in the groundwater table during dry and rainy periods are affected significantly by soil properties. Hence, the fluctuations in pore-water pressures, and stability of residual soil slopes are greatly influenced by the mechanical and hydraulic behaviour of the unsaturated soil [25, 26, 28, 41]. Therefore, it is necessary to understand the unsaturated soil mechanics principles, characterization and analyses of unsaturated soils and measurements of matric suction or negative pore-water pressures. This paper presents the principles of the unsaturated soil mechanics, the related apparatuses for measurement of unsaturated soil properties and numerical analyses incorporating unsaturated soil mechanics as well as the application of the unsaturated soil mechanics in engineering practise.

\section{Unsaturated soil mechanics}

Fredlund and Morgenstern [11] introduced the fourth phase for the unsaturated soil in addition to air, water and solid phases. That additional phase is called contractile skin or air-water interface (Fig. 2), acting like an elastic membrane that influences the mechanical behaviour of the soil by pulling the soil particles together through surface tension. Since atmospheric pore-air pressure $\left(u_{a}\right)$ is commonly encountered in the field, pore-air pressure is taken as a reference for the two independent stress state variables, net normal stress $\left(\sigma-u_{a}\right)$ and matric suction $\left(u_{a}-u_{w}\right)$, that are generally used in practice to distinguish the effects of normal stress and pore-water pressure $\left(u_{w}\right)$ changes, respectively $[11,13,35]$. The net normal stress is equivalent to the total normal stress $(\sigma)$ less the pore-air pressure.

Fredlund and Morgenstern [11] suggested two independent stress tensors to represent the stress state in an unsaturated soil, which are: 


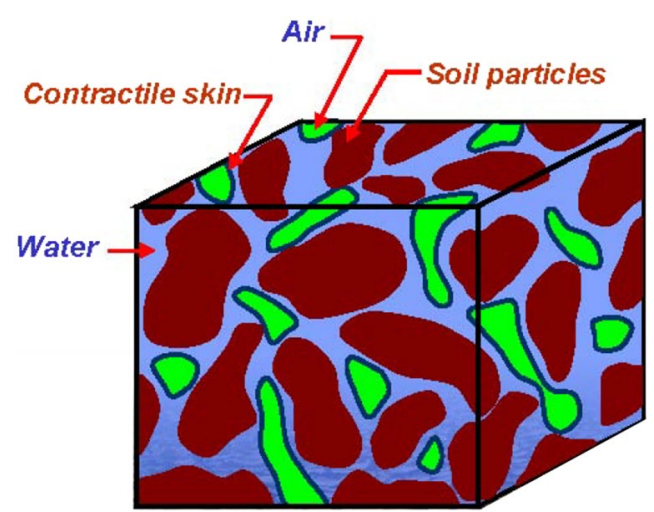

Fig. 2 Unsaturated soil phases (modified from Fredlund and Rahardjo [13])

$$
\begin{aligned}
& {\left[\begin{array}{ccc}
\left(\sigma_{x}-u_{a}\right) & \tau_{x y} & \tau_{x z} \\
\tau_{y x} & \left(\sigma_{y}-u_{a}\right) & \tau_{y z} \\
\tau_{z x} & \tau_{z y} & \left(\sigma_{z}-u_{a}\right)
\end{array}\right]} \\
& {\left[\begin{array}{ccc}
\left(u_{a}-u_{w}\right) & 0 & 0 \\
0 & \left(u_{a}-u_{w}\right) & 0 \\
0 & 0 & \left(u_{a}-u_{w}\right)
\end{array}\right]}
\end{aligned}
$$

Matric suction can be explained as a pore-water pressure with negative value with respect to the pore-air pressure. The changes in the water content within soil pores result in the changes in matric suction. Hence, the water flow within the unsaturated soil is affected by the less water-filled spaces among solid particles [55]. As a result, the permeability of the unsaturated soil varies with the changes in matric suction (called permeability function). The contractile skin generates a tension force on the soil particle when matric suction increases, resulting in the additional shear strength of the soil. In the opposite, the shear strength of the soil decreases when the water infiltration occurs since the matric suction decreases [14, 23].

Fredlund and Rahardjo [13] presented the constitutive equations for the unsaturated soil as summarized in Table 1 . The constitutive equations are required to relate the soil shear strength or volume change with stress state variables. Fredlund and Rahardjo [13] showed that all constitutive equations for the saturated soil can be extended to explain the mechanical behavior of the unsaturated soil. The constitutive equations for the unsaturated soil were developed with the consideration that there is a smooth transition from the unsaturated soil into the saturated soil when matric suction reaches zero or degree of saturation reaches $100 \%$.

The variation of soil water content with respect to suction is defined by soil-water characteristic curve (SWCC). It is commonly presented in a graph of either gravimetric water content $(w)$, volumetric water content $\left(\theta_{w}\right)$ or degree of saturation $(S)$ in the vertical axis against matric suction in the horizontal axis in a logarithmic scale [14]. Among the three possible representations of SWCC, SWCC in the form of degree of saturation (S-SWCC) incorporates soil volume change calculations and it is commonly assumed to be equal to pore-size distribution function. Thus, $S$-SWCC is normally adopted for 
Table 1 Equations for saturated and unsaturated soil mechanics. Summarized from Fredlund and Rahardjo [13]

\begin{tabular}{|c|c|c|c|c|}
\hline $\begin{array}{l}\text { Principle } \\
\text { or equation }\end{array}$ & Saturated soil & & Unsaturated soil & \\
\hline $\begin{array}{c}\text { Stress state } \\
\text { variables }\end{array}$ & $\left(\sigma-u_{w}\right)$ & (3) & $\left(\sigma-u_{a}\right)$ and $\left(u_{a}-u_{w}\right)$ & $(4)$ \\
\hline $\begin{array}{l}\text { Shear } \\
\text { strength }\end{array}$ & $\tau=c^{\prime}+\left(\sigma-u_{w}\right) \tan \phi^{\prime}$ & (5) & $\begin{array}{l}\tau=c^{\prime}+\left(u_{a}-u_{w}\right) \tan \phi^{b}+\left(\sigma-u_{a}\right) \tan \phi^{\prime} \\
c=c^{\prime}+\left(u_{a}-u_{w}\right) \tan \phi^{b}\end{array}$ & $\begin{array}{l}(6 a) \\
(6 b)\end{array}$ \\
\hline $\begin{array}{l}\text { Flow law } \\
\text { for water } \\
\text { (Darcys' } \\
\text { law) }\end{array}$ & $\begin{array}{l}v_{w}=-k_{s}\left(\partial h_{w} / \partial y\right) \\
h_{w}=y+\left(u_{w} / \rho_{w} g\right)\end{array}$ & (7) & $\begin{array}{l}v_{w}=-k_{w}\left(u_{a}-u_{w}\right)\left(\partial h_{w} / \partial y\right) \\
h_{w}=y+\left(u_{w} / \rho_{w} g\right)\end{array}$ & (8) \\
\hline $\begin{array}{l}\text { Unsteady } \\
\text { state seep- } \\
\text { age }\end{array}$ & $k_{s}=\left(\frac{\partial^{2} h_{w}}{\partial x^{2}}\right)+k_{s}\left(\frac{\partial^{2} h_{w}}{\partial y^{2}}\right)=m_{v} \rho_{w} g \frac{\partial h_{w}}{\partial t}$ & (9) & $\frac{\partial}{\partial x}\left(k_{w} \frac{\partial h_{w}}{\partial x}\right)+\frac{\partial}{\partial y}\left(k_{w} \frac{\partial h_{w}}{\partial y}\right)=m_{2}^{w} \rho_{w} g \frac{\partial h_{w}}{\partial t}$ & $(10)$ \\
\hline \multicolumn{5}{|c|}{ Slope stability based on limit equilibrium } \\
\hline $\begin{array}{l}\text { Moment } \\
\text { equilib- } \\
\text { rium }\end{array}$ & $F_{m}=\frac{\sum\left[c^{\prime} \beta R+\left\{N-u_{w} \beta\right\} R \tan \phi^{\prime}\right]}{\sum W x-\sum N f}$ & (11) & $F_{m}=\frac{\sum\left[C^{\prime} \beta R+\left\{N-u_{w} \beta \frac{\tan \phi^{b}}{\tan \phi^{\prime}}\right\} R \tan \phi^{\prime}\right]}{\sum W x-\sum N f}$ & $(12)$ \\
\hline $\begin{array}{l}\text { Force equi- } \\
\text { librium }\end{array}$ & $F_{f}=\frac{\sum\left[c^{\prime} \beta \cos \alpha+\left\{N-u_{w} \beta\right\} \tan \phi^{\prime} \cos \alpha\right]}{\sum N \sin \alpha}$ & (13) & $F_{f}=\frac{\sum\left[c^{\prime} \beta \cos \alpha+\left\{N-u_{w} \beta \frac{\tan \phi^{b}}{\tan \phi^{\prime}}\right\} \tan \phi^{\prime} \cos \alpha\right]}{\sum N \sin \alpha}$ & $(14)$ \\
\hline
\end{tabular}

where $N=$ normal force at the bottom of the slice, $\tau=$ shear stress, $h_{w}=$ hydraulic head,$c^{\prime}=$ effective cohesion, $g=$ gravitational force, $c=$ cohesion, $y=$ elevation, $\phi^{\prime}=$ effective friction angle, $\beta=$ the slope length at the bottom of the slice, $\rho_{w}=$ density of water, $t=$ time, $\phi^{b}=$ angle indicating the increase in shear strength due to matric suction, $k_{s}=$ saturated permeability, $v_{w}=$ water flow velocity, $k_{w}=$ water permeability function, $\partial h_{w} / \partial_{y}=$ gradient of hydraulic head in $y$-direction, $m_{2}^{W}=$ ratio of water volume change against changes in matric suction, $W=$ total weight of the slice, $\alpha=$ the angle between horizontal and tangent to the midpoint of the bottom of each slice

representing probability of random pore connections [57], since the region within the pore-suction distribution function defines the degree of saturation.

An important parameter of the SWCC for unsaturated soil mechanics is the air-entry value (AEV), associated with matric suction where water starts to be drained out from the biggest soil pores [5]. Alternatively, AEV could be equivalently defined as the matric suction that breaks the meniscus formed by water surface tension in the largest pores [15]. The AEV has been found to depend on the grain size distribution of the soil. A larger proportion of fine particles implies smaller intra-particle pore spaces between soil particles, resulting in a higher AEV [4]. On the other hand, the residual suction refers to the suction beyond which there is no significant removal of water from the soil with the increase in suction.

Common laboratory experiments to determine SWCC only yield few data points along the SWCCs. For the purpose of numerical analyses, a continuous SWCC along the suction range is needed. This could be obtained by best-fitting the discrete data points from laboratory experiments using the Fredlund and Xing [15] equation, developed using the least-square method:

$$
\theta_{w}=C(\psi) \frac{\theta_{s}}{\left\{\ln \left[e+\left(\frac{\psi}{a}\right)^{n}\right]\right\}^{m}} ; \quad C(\psi)=1-\frac{\ln \left(1+\frac{\psi}{\psi_{r}}\right)}{\ln \left(1+\frac{10^{6}}{\psi_{r}}\right)}
$$


where, $\theta_{w}=$ calculated volumetric water content, $\theta_{s}=$ volumetric water content at saturated condition, $\psi=$ suction of the soil, $a, \mathrm{n}$ and $\mathrm{m}=$ fitting parameters, $C(\psi)=$ Correction function that forces SWCC through a suction of $10^{6} \mathrm{kPa}$ and zero water content, and $\psi_{r}=$ Suction at which residual water content occurs.

Leong and Rahardjo [33] suggested that $C(\psi)=1$ in Eq. 15 to obtain a better SWCC fitting in the low-suction range (less than $500 \mathrm{kPa}$ ), although compromising the fitting accuracy at the higher suction range. In addition, due to the close relationship between SWCC and coefficient of permeability, $k_{s}$ [7], it is possible to estimate the permeability function of unsaturated soils from the available SWCC and $k_{s}$. Mualem [36] classified various prediction models for the permeability functions by different researchers into three groups: empirical, macroscopic, and statistical models. Leong and Rahardjo [34] later found that the statistical model is the most rigorous and yields the most accurate permeability function. The permeability function can be estimated statistically using the equation developed by Kunze et al. [32] and best-fitted using the equation developed by Leong and Rahardjo [34] to form a continuous permeability function curve.

The shear strength of soil is a requisite input parameter for slope stability analyses. The saturated shear strength is governed by Eq. 5 and is illustrated by the Mohr-Coulomb failure envelope [53], while the unsaturated shear strength is governed by Eq. 6 [12] as illustrated by the Extended Mohr-Coulomb failure envelope in Fig. 3.

\section{Measurement of unsaturated soil properties}

Unsaturated soil properties play important roles in affecting the rate of rainwater infiltration and factor of safety variations with time. Therefore, it is important to characterize the hydraulic and mechanical properties of unsaturated soil with the appropriate apparatuses. The hydraulic properties, i.e., a soil-water characteristic curve (SWCC) and a permeability function are required for seepage analyses or analyses of water flow throughout soil pores with respect to variations in matric suctions. The mechanical properties, i.e. unsaturated shear strength is required for stability analyses of soil slope varying matric suctions.

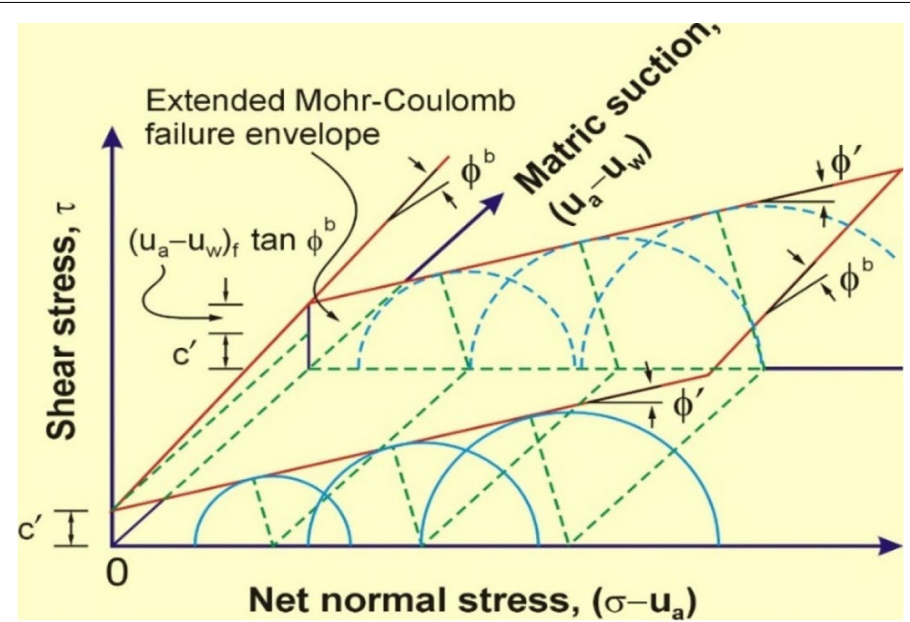

Fig. 3 Extended Mohr-Coulomb failure envelope (Fredlund and Rahardjo [12]) 


\section{Soil-water characteristic curve}

Matric suction is equivalent to the difference in pore-air and pore-water pressures. In the field, pore-air pressure is equivalent to zero at the atmospheric condition. Therefore, matric suction is also referred to as the negative pore-water pressure [47]. In SWCC tests, the matric suction is applied to the soil specimen through the application of pore-air pressure using the axis translation technique as introduced by Hilf [20]. Through this procedure, the applied pore-water pressure is kept at atmospheric pressure, resulting in pore-water pressure equal to zero. Therefore, the magnitude of the matric suction is equal to the applied air pressure. The conventional methods for measurement of SWCC commonly involve Tempe cell and pressure plate for a suction range up to $100 \mathrm{kPa}$ and $1500 \mathrm{kPa}$, respectively [2].

The alternative method for rapid measurement of SWCC is the small-scale centrifuge test. This test can generate SWCC for suctions up to $250 \mathrm{kPa}$. A special chamber (Fig. 4a) is used to place the soil specimen against different centrifugal force. The matric suctions are generated by applying different angular velocities of the centrifuge. The removal of water from the soil at a certain angular velocity is measured by weighing the specimen. SWCC is produced by plotting the different amounts of water against the respective angular velocities. Initially, a cylindrical soil specimen with a diameter of $70 \mathrm{~mm}$ and a height of $20 \mathrm{~mm}$ is saturated. The saturation process is carried out by placing the soil specimen inside a container which is connected to the water level higher than the height of the specimen. The difference in height of water level is meant to apply a different gradient which will force water to flow into the soil specimen. After the saturation, the soil specimen is weighed and then is placed in a steel ring (Fig. 4b). This steel ring will then again be placed into the mould. This mould will then be put in a specimen holder (Fig. 4b). The specimen holders are placed at the

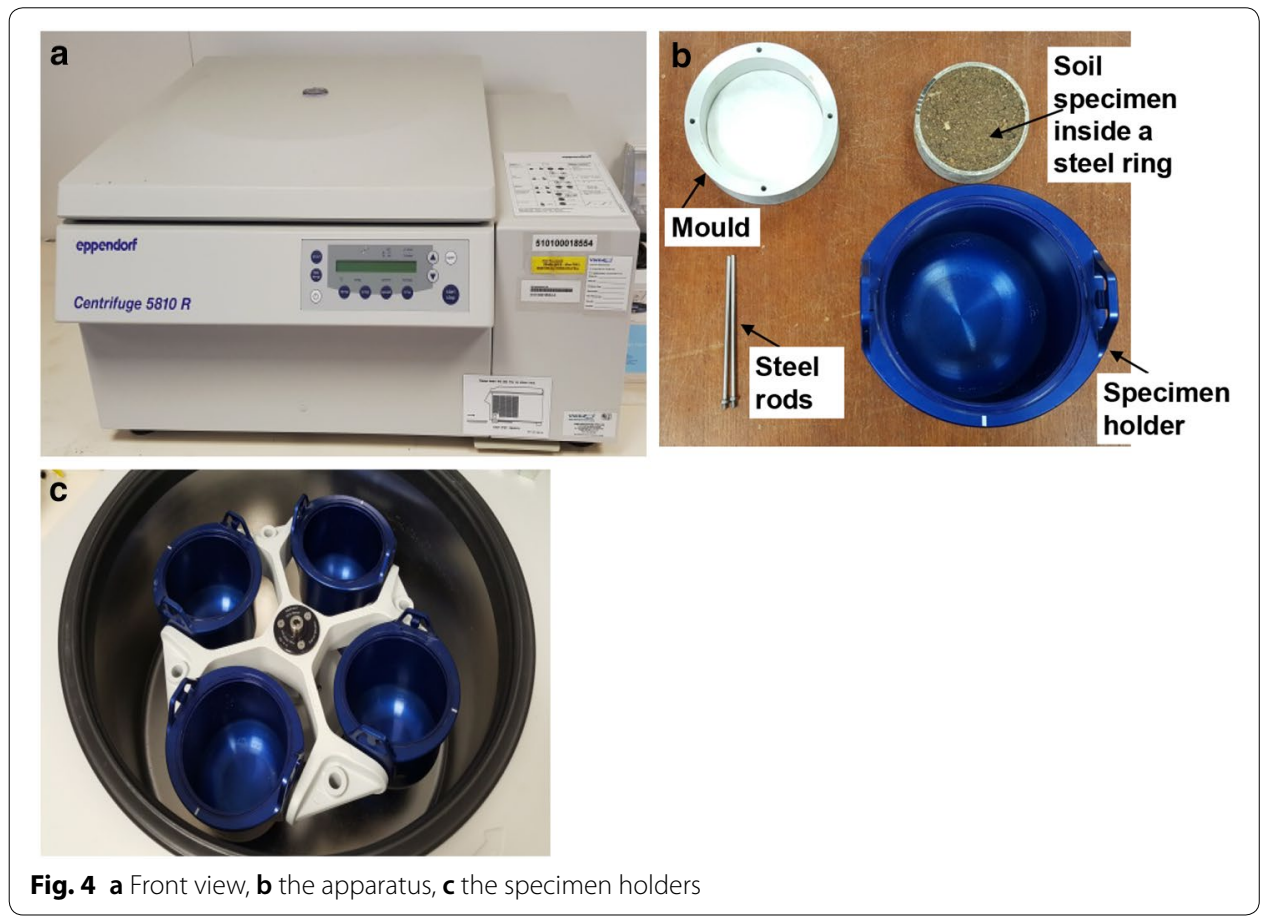


opposite sides to maintain the balance of the small-scale centrifuge machine (Fig. 4c). The test is performed at incremental angular velocities for specified durations. The angular velocities that are applied to the specimens varied from $200 \mathrm{rpm}$ to $3900 \mathrm{rpm}$. The matric suction is calculated using Eq. 16.

$$
\psi=\frac{\left(\mathrm{r}_{1}^{2}-\mathrm{r}_{2}^{2}\right) *\left(\rho \omega^{2}\right)}{2}
$$

where, $\psi=$ soil suction $(\mathrm{kPa}), \mathrm{r}_{1}=$ distance to the center of soil specimen $(\mathrm{m}), \mathrm{r}_{2}=$ distance to the free water surface $(\mathrm{m}), \omega=$ velocity $(\mathrm{rad} / \mathrm{s}), \rho=$ pore fluid density $\left(\mathrm{kg} / \mathrm{m}^{3}\right)$.

The other alternative method for rapid measurement of SWCC is the evaporation method using HYPROP (Fig. 5). This method is able to establish SWCC for suctions up to $100 \mathrm{kPa}$. The experimental works are carried out based on the evaporation method proposed by Schindler and Muller [50]. The test is carried out using a pair of tensiometer shafts with ceramic tips located at different depths of the specimen. One tensiometer is positioned at $1 / 4$ of the height of the specimen from the soil surface and the other at $3 / 4$ of the height of the specimen. The tensiometers can measure suctions within a range from $0 \mathrm{kPa}$ to $100 \mathrm{kPa}$ and they have a capacity of 1 Bar each. The two tensiometer readings are then averaged to obtain the representative suction experienced by the specimen. During the test, the gravimetric water content of the specimen can be determined from mass measurements using an electronic balance. The SWCC can then be obtained by plotting gravimetric water content against the average soil suction.

Measurement of SWCC for suctions beyond $500 \mathrm{kPa}$ is normally carried out using dewpoint potentiometer method such as WP4C. WP4C is one of the common apparatuses used by researcher incorporating this method (Fig. 6). Fredlund et al. [14] describe the process used by a potentiameter to measure the water activity in a soil specimen. The specimen is thermodynamically equilibrated to measure the suction pressure at a particular water content. The specimen should be fitted into a stainless-steel dish before placing it inside the temperature-controlled chamber of the potentiameter. The chamber is sealed before the reading process commences. The mirror is then cooled to the dew-point temperature using a Peltier cooling system while a thermocouple measures the temperature of the mirror. The dew-point temperature is recorded as condensation begins to occur on the mirror. A photoelectric sensor is used to sense this condensation while an infrared thermometer is used

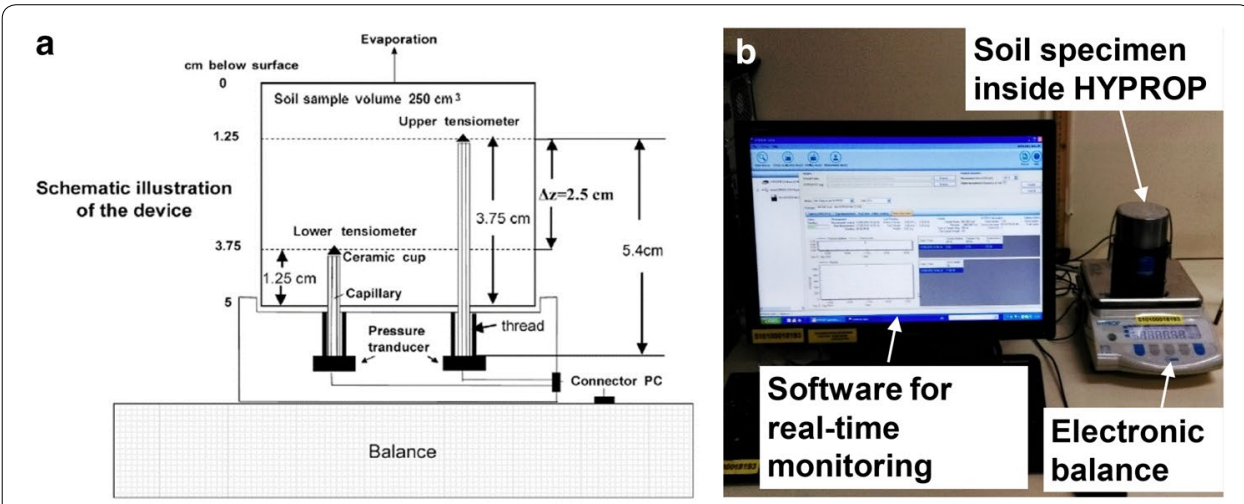

Fig. 5 a Schematic diagram of HYPROP and $\mathbf{b}$ Actual experiment setup of HYPROP 


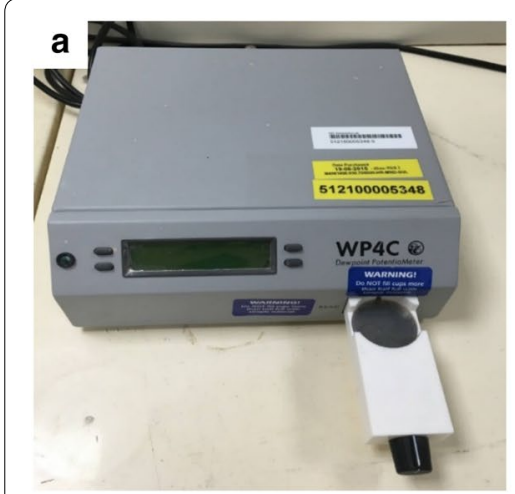

b

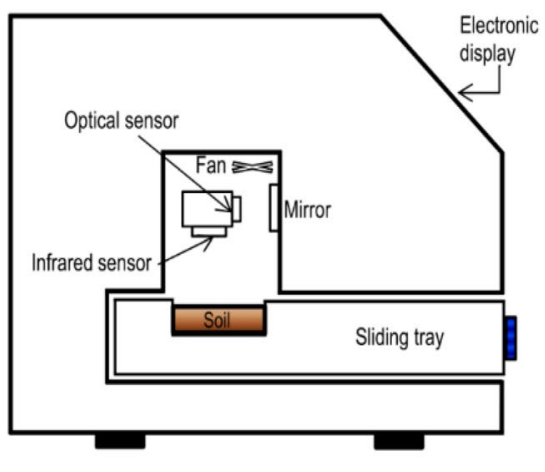

Fig. 6 a Photo of WP4C and $\mathbf{b}$ schematic diagram of dew-point potentiometer using WP4C

to measure the temperature of the chamber. The water vapour pressure above the specimen and the saturated water vapour pressure are then measured. The total suction of the specimen can be calculated using Eq. 17.

$$
\Psi=\frac{R T}{M} \times \ln \frac{p}{p_{0}}
$$

where, $\Psi=$ total suction of the soil specimen $(\mathrm{kPa}), R=$ gas constant $(8.31 \mathrm{~J} / \mathrm{molK})$, $T=$ temperature of the specimen ( $\left.{ }^{\circ} \mathrm{K}\right), M=$ molecular mass of water, $p=$ vapour pressure of the air in the sealed chamber $(\mathrm{kPa}) ; p_{0}=$ saturation vapour pressure at the specimen temperature $(\mathrm{kPa})$.

Fredlund [10] indicated that variables of SWCC (residual water content, residual suction, air-entry value, and inflection point) can only be obtained if the SWCC is plotted with respect to degree of saturation. However, the water content obtained from SWCC through Tempe Cell, pressure plates, small-scale centrifuge, HYPROP and dew-point potentiameter for certain matric suctions is expressed in term of gravimetric water content. To plot the SWCC with respect to degree of saturation, measurements of the total volume of the soil specimen should be conducted through shrinkage test. A soil specimen with a typical diameter of $50 \mathrm{~mm}$ and a height of $30 \mathrm{~mm}$ should be saturated prior to the shrinkage test. After saturation, the diameter and height of the soil specimen at various points are measured daily using a Vernier Caliper. In addition, the mass of the soil specimen is also weighed daily. A plot between void ratio (e) and gravimetric water content (w) can then be obtained. A hyperbolic curve as proposed by Fredlund et al. [16] can be utilized for best-fitting the shrinkage curves as given in Eq. 18. The volumetric water content can be estimated from the void ratio using Eq. 19 [14].

$$
e(w)=a_{s h}\left[\frac{w^{c_{s h}}}{b_{s h} c_{s h}}+1\right]^{\left(\frac{1}{c_{s h}}\right)}
$$

where, $e=$ void ratio, $a_{s h}=$ value of minimum void ratio $\left(e_{m i n}\right), b_{s h}=$ slope of the line of tangency, $c_{s h}=$ curvature of the shrinkage curve, $w=$ corresponding gravimetric water content.

$$
\theta_{w}=V_{s}(1+e)
$$


where, $\theta_{w}=$ volumetric water content, $V_{s}=$ value of the volume of solids in the soil specimen, $e=$ void ratio obtained from the plot of $e$ versus $w$.

\section{Permeability function}

Permeability function can be obtained using indirect measurement or direct measurement. Triaxial permeameter following the design by Goh et al. [18] can be used for the direct measurement of unsaturated permeability. The unsaturated permeability test is carried out by creating a hydraulic head gradient within the soil specimen at a given matric suction. Inflow and outflow rates are continuously recorded with an interval of $5 \mathrm{~min}$. The test is ceased when both flow rates are approximately the same (i.e. steady-state condition). The measurement of unsaturated permeability is influenced significantly by the ceramic disks on the bottom and top pedestals. The calculation of permeability of the whole specimen setup still follows Darcy's Law, however due to the three-layered system of the setup (i.e. Disk-Soil-Disk), the equation used to determine the unsaturated permeability coefficient is modified as shown in Eq. 20.

$$
k_{w}=\frac{L_{s}}{\left(\frac{L}{k}-\left(\frac{L_{t}}{k_{t}}+\frac{L_{b}}{k_{b}}\right)\right)}
$$

where, $k_{w}=$ coefficient of unsaturated permeability $(\mathrm{m} / \mathrm{s}), k=$ measured coefficient of permeability of setup $(\mathrm{m} / \mathrm{s}), k_{b}=$ coefficient of permeability of bottom disk $(\mathrm{m} / \mathrm{s})$, $k_{t}=$ coefficient of permeability of top disk (m/s), $L=$ total Length $(\mathrm{m}), L_{s}=$ length of soil specimen (m), $L_{b}=$ length of bottom disk (m), $L_{t}=$ length of top disk (m).

The alternative method for direct measurement of the permeability function is the evaporation method using HYPROP. This method assumes the water flow through a horizontal plane at midpoint between the tensiometer tips for a given interval of time. As a result, permeability of soil specimen at this midpoint during the water flow process can be calculated using Eq. 21. This is similar to the instantaneous profile method as presented by Krisdani et al. [31].

$$
q_{i}=\frac{\Delta V_{i} / \Delta t_{i}}{2 A}
$$

where, $\Delta V_{i}$ =water reduction $\left(\mathrm{cm}^{3}\right)$ over the mass change, $q_{i}=$ the rate of water flow $(\mathrm{m} / \mathrm{s}), A=$ the cross-sectional area $\left(\mathrm{cm}^{2}\right)$ of the column, $\Delta t_{i}=$ the interval of time between two measurements.

The permeability of soil is then calculated from Darcy's equation:

$$
k_{i}\left(h_{i}\right)=-\frac{q_{i}}{\left\{\left(\frac{\Delta h_{i}}{\Delta z}\right)-1\right\}}
$$

where, $h_{i}=$ time- and space-averaged suction, $\Delta h_{i}$ is the difference of the two suctions measured at two measuring levels, $\Delta z$ is the height difference of the tensiometer tips.

Based on Eq. 22, different values of coefficient of permeability can be calculated for each average soil suction obtained from the HYPROP at individual time intervals. The instantaneous value of permeability can be plotted against the corresponding soil suction to obtain the unsaturated permeability of the soil. 
For the indirect measurement of unsaturated permeability, the statistical model [7] is commonly used to determine the permeability function from SWCC together with the saturated permeability of soil (Eq. 23).

$$
k_{w}\left(\theta_{w}\right)_{i}=\frac{k_{s}}{k_{s c}} A_{d} \sum_{j=1}^{m}\left[(2 j+1-2 i)\left(u_{a}-u_{w}\right)_{j}{ }^{-2}\right]
$$

where: $k_{w}\left(\theta_{w}\right)_{i}=$ coefficient of permeability $(\mathrm{m} / \mathrm{s})$ which is calculated under a certain volumetric water content $\left(\left(\theta_{w}\right)_{i}\right) ; i=$ increasing interval number with respect to the decreasing value of volumetric water content, $k_{s}=$ coefficient of permeability (saturated) obtained through measurements $(\mathrm{m} / \mathrm{s}), k_{s c}=$ coefficient of permeability (saturated) obtained through calculations $(\mathrm{m} / \mathrm{s}), A_{d}=$ adjusting constant equal to $\frac{T_{s}^{2} \rho_{w} g \theta_{s}^{p}}{2 \mu_{w} N^{2}}\left(\mathrm{~m} . \mathrm{s}^{-1}\right.$. $\left.(\mathrm{kPa})^{2}\right), T_{s}=$ surface tension of water $\left(\mathrm{mN} \mathrm{m}^{-1}\right), \rho_{w}=$ density of water $\left(1000 \mathrm{~kg} / \mathrm{m}^{3}\right)$, $g=$ value of gravitational acceleration $\left(\mathrm{m} / \mathrm{s}^{2}\right), \mu_{w}=$ absolute viscosity of water (Pa s), $\theta_{s}=$ volumetric water content at saturation, $p=$ a constant value to represent the relationship of pores under different sizes, $N=$ the number of intervals calculated from zero volumetric water content to the saturated volumetric water content, $j=$ a counter from " $\mathrm{i}$ " to " $\mathrm{m}$ ", $m=$ the number of intervals from the saturated volumetric water content, $\theta_{s}$ (where $\mathrm{i}=1$ ) to the lowest volumetric water content, $\theta_{L}$ (where $\mathrm{i}=\mathrm{m}$ ); $u_{a}-u_{w}=$ matric suction corresponding to the $j$ th interval.

\section{Unsaturated shear strength}

The unsaturated soil shear strength tests are conducted using a modified triaxial cell (Fig. 7) which incorporates high air-entry ceramic disc to control suctions during unsaturated shear strength test [42]. The axis translation technique is implemented in the unsaturated shear strength testing to avoid cavitation (at $100 \mathrm{kPa}$ negative water pressure) of water in the pore-water pressure line [20].

The new development in unsaturated soil mechanics allows the simulation of rainfallinduced slope failure via triaxial shearing-infiltration tests. The stress path obtained from a consolidated drained (CD) triaxial test under a constant matric suction and from an infiltration test under a constant deviator stress is presented in Fig. 8. The tests can be carried out using a modified triaxial apparatus as presented by Wong et al. [56]. In this

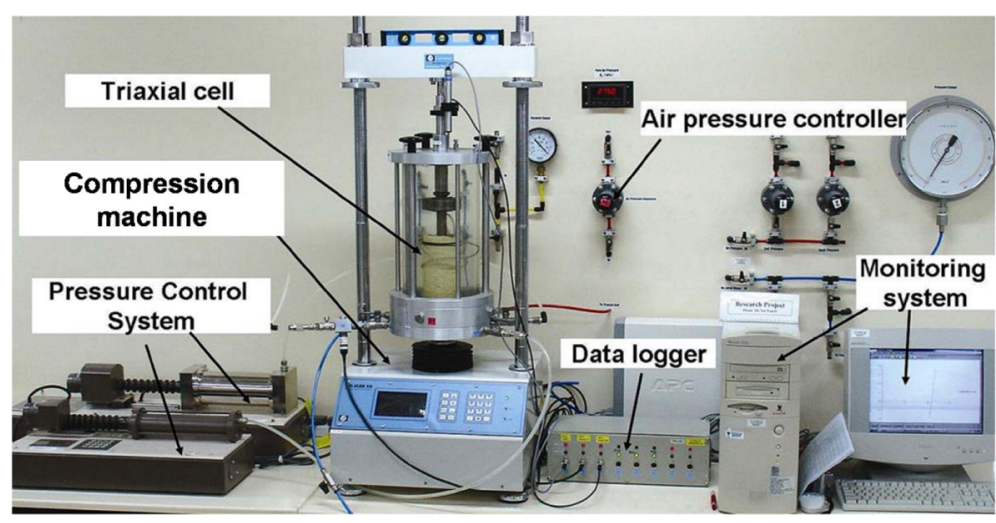

Fig. 7 Configuration of unsaturated triaxial testing 


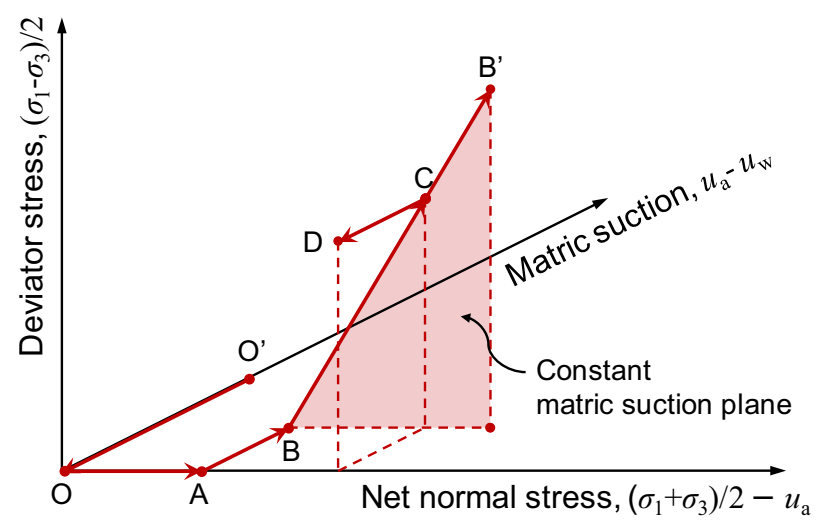

Fig. 8 Stress paths of soil specimen during triaxial shearing-infiltration test [29]

test, the infiltration can be commenced once the shear stress of the specimen reached $85-90 \%$ of the peak deviator stress [19]. In the infiltration stage, a constant deviator stress (i.e., $85-90 \%$ of the peak deviator stress) should be maintained while water is injected from the base of the triaxial at a constant rate of $0.04 \mathrm{~mm}^{3} / \mathrm{s}$ [43]. The deviator stress is simultaneously maintained constant and therefore, there is no shear strain applied to the specimen. Nanyang Technological University (NTU) mini suction probes can be used to measure matric suctions in a soil specimen during the tests [43]. Note that during water injection to the specimen (i.e., infiltration), the pore-air pressure is under a drained condition.

\section{Application of unsaturated soil mechanics in slope stabilization}

Numerous slope failures frequently occur in steep residual soil slopes with a deep groundwater table during rainfalls. A significant thickness of unsaturated soil zone above the groundwater table is a general characteristic of steep residual soil slopes. Negative pore-water pressures or matric suctions as a crucial part of the stability of residual soil slopes are needed to be maintained in a slope under varying climatic conditions and to be considered in the slope assessment. Infiltration of rainwater into the slope surface contributes to raising the groundwater table and decreasing matric suctions. The reduction of matric suction in unsaturated residual soils results in a decrease in shear strength of the soil along the potential slip surface [12]. As rainwater infiltration into soil slopes is the major cause of rainfall-induced landslides, it is important to protect the slope with preventive measures that can avert or minimize rainwater infiltration into the slope. One of the common applications of unsaturated soil mechanics to slope stabilization is in the design and construction of a capillary barrier system (CBS) as a slope cover to minimize rain infiltration into slopes.

\section{Capillary barrier system (CBS)}

CBS works following the unsaturated soil mechanics concepts. It consists of two layers of non-cohesive fine-grained and coarse-grained soils. Both layers have contrasting unsaturated hydraulic properties (i.e., soil-water characteristic curve and permeability function). Figure 9 explains the principle of capillary barrier system. Under unsaturated 

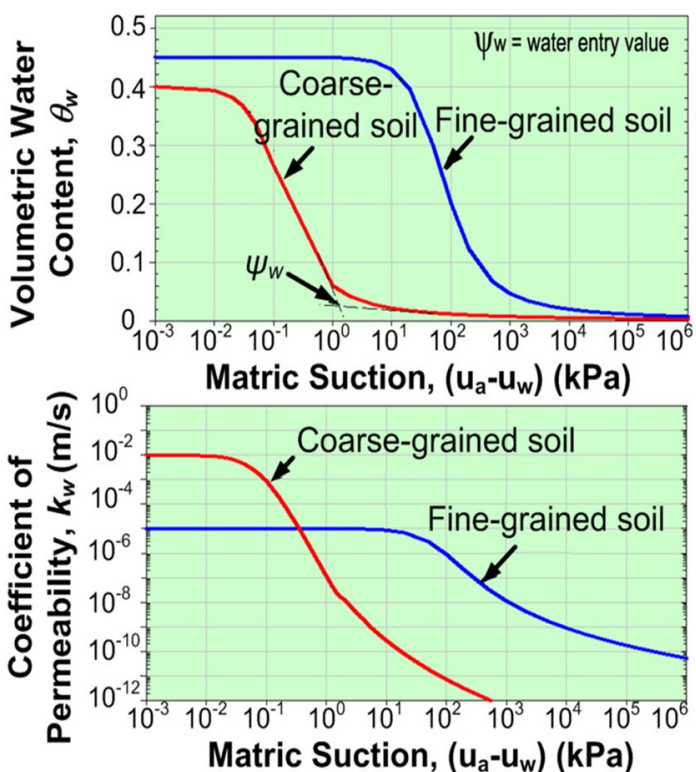

Fig. 9 Soil-water characteristic curves and permeability function of capillary barrier system

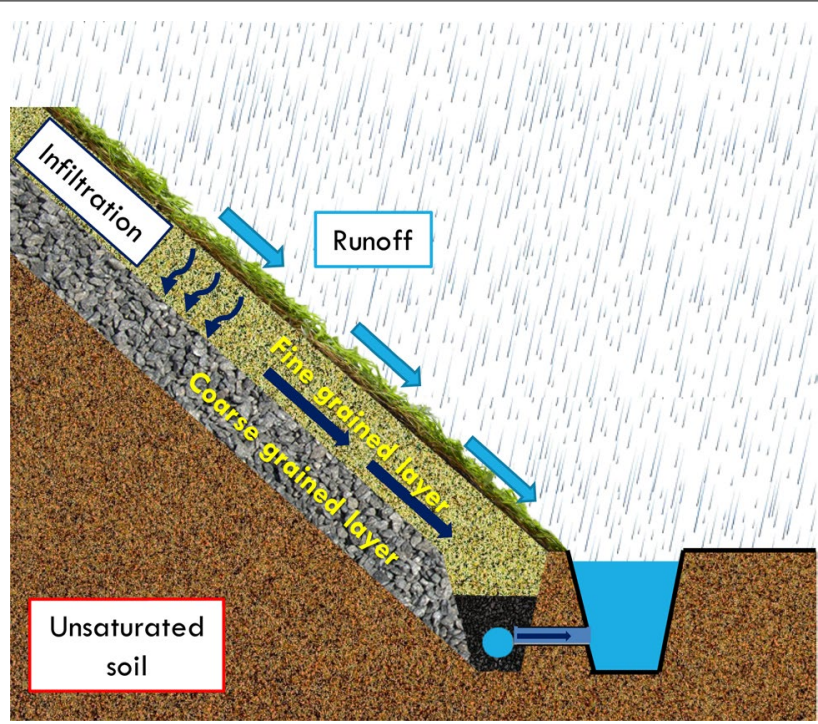

Fig. 10 Mechanism of capillary barrier system

condition, the permeability of the coarse-grained soil is lower than that of the fin-grained soil. Hence, the barrier effect is generated within the coarse-grained layer and water only flows along the fine-grained layer which can be removed through evaporation, transpiration or lateral drainage located at the toe of the slope. Figure 10 shows the mechanism of CBS in minimizing the infiltration of rainwater into the slope.

In order to ensure the effectiveness of CBS performance, the selection of CBS materials must be carried out carefully following three main criteria as studied by Rahardjo et al. [48]. Those controlling parameters in selecting CBS materials are: the water-entry 
value of the coarse-grained layer, the ratio between the water-entry value of the finegrained layers and the coarse-grained layers ( $\psi_{w}$-ratio), and the saturated coefficient permeability of the fine-grained layer. The $\psi_{w}$-ratio between fine- and coarse-grained layers should be higher than 10 in order to generate a good barrier effect and to reduce the rainwater infiltration into the coarse-grained layer. The water-entry value of the coarsegrained layer must be less than $1 \mathrm{kPa}$. The saturated permeability of the fine-grained layer must be higher than $10^{-5} \mathrm{~m} / \mathrm{s}$ in order to ensure that water can be drained out rapidly from the fine-grained layer through lateral diversion.

Study by Tami et al. [52] indicated that additional criteria should be satisfied to ensure the effectiveness of CBS. The presence of fines content within the fine-grained layer should be low enough to maintain the steepness of SWCC and to ensure a large amount of water can be drained out from the fine-grained layer. Hence, the storage capacity of the fine-grained layer can return to normal quickly after the rain stops. In addition, the fine-grained layer can be prevented from the development of cracks if the presence of fines content is low, especially during dry period when matric suctions are high.

\section{Numerical analyses of slope stability with and without capillary barrier system}

Comprehensive numerical analyses were carried out to illustrate the stability of unsaturated soil slopes subjected to a prolonged rainfall. Typical soil slopes with and without a slope cover CBS were compared to study their performance under the prolonged rainfall. The slope is composed of the residual soil from the sedimentary Jurong Formation. The CBS is comprised of fine recycled concrete aggregate (FRCA) and coarse recycled concrete aggregate (CRCA) as the capillary barrier components.

\section{Material properties of residual soil and CBS}

Laboratory tests were carried out to determine saturated and unsaturated properties of the residual soil, fine recycled concrete aggregate (FRCA) and coarse recycled concrete aggregate (CRCA) used in this study.

The grain size analyses and classification of soil and RCA were determined according to ASTM [3] D422 and ASTM [1] D2487-11, respectively. The residual soil can be classified in accordance with the Unified Soil Classification System (USCS) as highly plastic clay (CH). The CRCA could be classified as Poorly graded gravel (GP) while the CRCA is classified Poorly graded sand (SP). The index properties of the residual soil, FRCA, and CRCA are summarized in Table 2.

The SWCC tests were carried out using Tempe cell apparatus following procedures described in the previous section. The details of the SWCC tests under a drying process for FRCA and CRCA are similar to those explained by Rahardjo et al. [49]. For low matric suction controls, a U-type tube manometer was used to control water pressure head and the readout from the head difference reflects the matric suction. The measured SWCCs were best-fitted by the Fredlund and Xing [15] equation with the correction factor taken as 1 as suggested by Leong and Rahardjo [33]. The best-fitting parameters for the drying SWCC (a, n, and $\mathrm{m}$ ) of the residual soil, FRCA and CRCA are tabulated in Table 3.

The permeability functions for the residual soil, FRCA and CRCA were determined from SWCC and saturated permeability using the statistical method as proposed by 
Table 2 Index properties of residual soil, fine RCA, and coarse RCA

\begin{tabular}{llll}
\hline Properties & Residual soil & FRCA & CRCA \\
\hline USCS classification & $\mathrm{CH}^{\mathrm{a}}$ & $\mathrm{SP}$ & $\mathrm{GPC}$ \\
Specific gravity, $\mathrm{G}_{s}$ & 2.61 & 2.57 & 2.66 \\
Porosity, $n$ & 0.440 & 0.390 & 0.437 \\
Unit weight, $\gamma_{t}\left(\mathrm{kN} / \mathrm{m}^{3}\right)$ & 20.3 & 19.0 & 20.0 \\
Natural water content, $w(\%)$ & 38 & 6.70 & 6.56 \\
Optimum water content, $w_{\text {opt }}(\%)$ & 11 & $\mathrm{NA}$ & $\mathrm{NA}$ \\
\hline
\end{tabular}

a Highly plastic clay

b Poorly graded sand

c Poorly graded gravel

Table 3 Hydraulic properties of residual soil, fine RCA, and coarse RCA

\begin{tabular}{llll}
\hline Properties & Residual soil & FRCA & CRCA \\
\hline Saturated volumetric water content, $\theta_{s}$ & 0.423 & 0.387 & 0.437 \\
Air entry value, $\psi_{a}(\mathrm{kPa})$ & 112.5 & 7.02 & 0.13 \\
Water entry value, $\psi_{w}(\mathrm{kPa})$ & 1500 & 50 & 0.8 \\
Residual matric suction, $\psi_{r}(\mathrm{kPa})$ & 1576 & 16.24 & 0.43 \\
Residual volumetric water content, $\theta_{r}$ & 0.042 & 0.001 & 0.031 \\
Fredlund and Xing $[15]$ parameters for predicting SWCC drying curve & & \\
a (kPa) & 1630 & 10 & 0.20 \\
$\mathrm{n}$ & 1.06 & 5 & 6 \\
$\mathrm{~m}$ & 7 & 1.2 & 1.2 \\
Saturated permeability, $\mathrm{k}_{s}(\mathrm{~m} / \mathrm{s})$ & $1.0 \times 10^{-9}$ & $1.2 \times 10^{-6}$ & $4.0 \times 10^{-3}$ \\
\hline
\end{tabular}

Childs and Collis-George [7]. Figure 11 shows the drying SWCCs and permeability functions of the residual soil, FRCA, and CRCA. The water-entry value, $\psi_{w}$, of FCRA and CRCA are $50 \mathrm{kPa}$ and $0.8 \mathrm{kPa}$, respectively. The $\psi_{w}$-ratio between fine and coarse RCA was 62.5 that was greater than 10; therefore, this combination of FRCA and CRCA can make a good capillary barrier system [40]. The saturated coefficients of permeability, $k_{s}$, for FRCA and CRCA are $1.2 \times 10^{-6} \mathrm{~m} / \mathrm{s}$ and $4.0 \times 10^{-3}$ $\mathrm{m} / \mathrm{s}$, respectively. The $k_{s}$ of CRCA is higher than $1.0 \times 10^{-5} \mathrm{~m} / \mathrm{s}$ to ensure that water can flow effectively through the fine-grained layer.

The elastic modulus and shear strength properties of the residual soil as well as all the materials used for the CBS were tested in the laboratory. Consolidated undrained $(\mathrm{CU})$ saturated triaxial tests with pore-water pressure measurements were carried out to measure the saturated shear strength parameters $\left(c^{\prime}\right.$ and $\left.\phi^{\prime}\right)$ of the residual soil and consolidated drained $(\mathrm{CD})$ saturated triaxial tests were also performed to measure the saturated shear strength parameters of FRCA and CRCA. The multistage consolidated drained (CD) unsaturated triaxial tests were carried out to measure the unsaturated shear strength parameters $\left(\phi^{b}\right)$ of the residual soil, FRCA and CRCA (Fig. 12). The mechanical properties of the residual soil, FRCA, and CRCA are summarized in Table 4. 




a SWCC

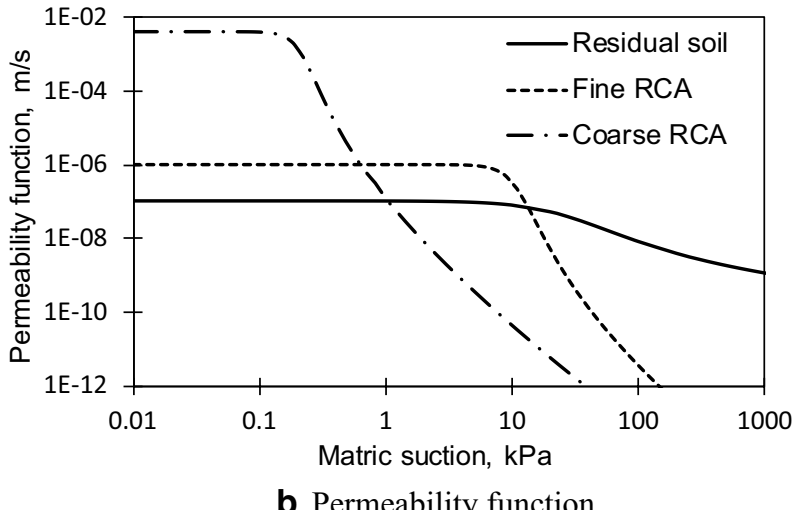

Fig. 11 Hydraulic properties of residual soil, FRCA and CRCA
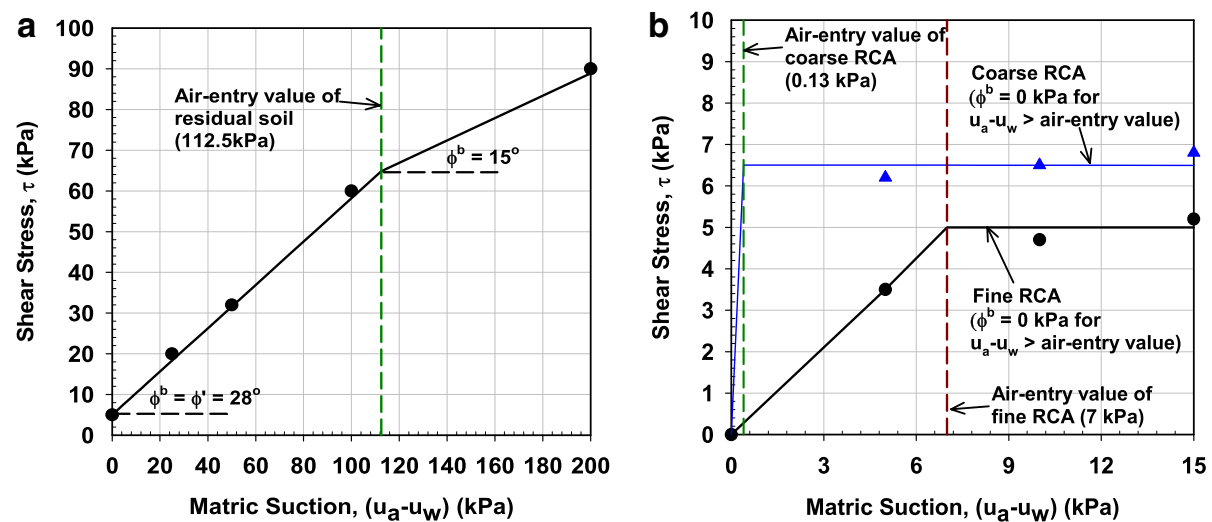

Fig. 12 Unsaturated shear strength of $\mathbf{a}$ residual soil and $\mathbf{b}$ fine and coarse RCA

\section{Seepage, deformation and stability analyses}

Seepage analyses (i.e., SEEP/W) were conducted to compute the pore-water pressure changes due to rainfall infiltration. The computed pore-water pressure distributions were then used as an initial condition in both stress-strain analyses (i.e., SIGMA/W) 
Table 4 Mechanical properties of residual soils, fine RCA, and coarse RCA

\begin{tabular}{|c|c|c|c|}
\hline Properties & Residual soil & FRCA & CRCA \\
\hline Elastic modulus, E (kPa) & 6000 & 18,000 & 210,000 \\
\hline Poison's ratio, $v$ & 0.4 & 0.33 & 0.33 \\
\hline Effective cohesion, $c^{\prime}(\mathrm{kPa})$ & 5 & 0 & 0 \\
\hline Effective friction angle, $\phi^{\prime}\left({ }^{\circ}\right)$ & 28 & 34 & 35 \\
\hline $\begin{array}{l}\text { Angle indicating the increase in shear strength due to } \\
\text { the increase in suction, } \phi^{b}\left({ }^{\circ}\right)\end{array}$ & 15 & 0 & 0 \\
\hline
\end{tabular}

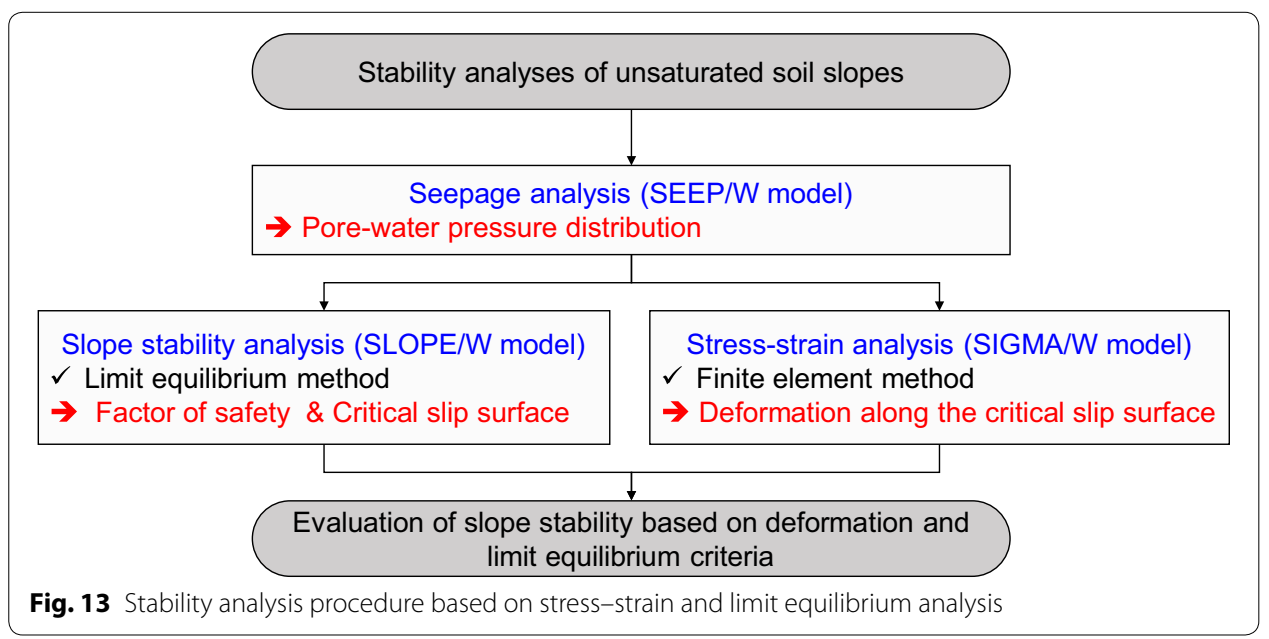

to assess the slope deformation and slope stability analyses (i.e., SLOPE/W) to assess the factor of safety of the slope.

The induced horizontal and vertical displacements at three different locations, such as slope crest, slope midpoint, and slope toe that corresponded to the position of a critical slip surface inferred from slope stability analyses were investigated. Based on the slope deformations, a dimensionless displacement $\left(E_{s} \delta_{\max } / \gamma_{t} H^{2}\right)$ given by Kim et al. [27] and Zienkiewicz et al. [58] was calculated to define instability of the slope, where $E_{S}$ is the Young's modulus of the soil, $\delta_{\max }$ is the maximum displacement of the slope along the critical slip surface, $\gamma_{t}$ is the unit weight, and $H$ is the slope height. To find the time at failure, two tangent lines were drawn on the relationship between the dimensionless displacement versus elapsed time. The intersection points of these tangent lines indicate the failure condition of the slope. The procedure for evaluating the unsaturated soil slope stability followed in this study is summarized succinctly in Fig. 13.

First, seepage analyses were conducted using a numerical model of soil slope using SEEP/W [17] software. The slope of a $4 \mathrm{~m}$ height with an inclination angle of $45^{\circ}$ was modelled in this study as a typical slope in Singapore, as shown in Fig. 14a. Figure 14b shows the slope covered with the CBS that is constructed with $400 \mathrm{~mm}$ thickness of FRCA and $200 \mathrm{~mm}$ thickness of CRCA. The groundwater table was assumed at a typical position in residual soil slopes in Singapore. The infiltration process of the rainwater into the soil was simulated using a saturated-unsaturated finite element analysis. The boundary conditions used for the transient seepage analysis are also shown in Fig. 14. The 


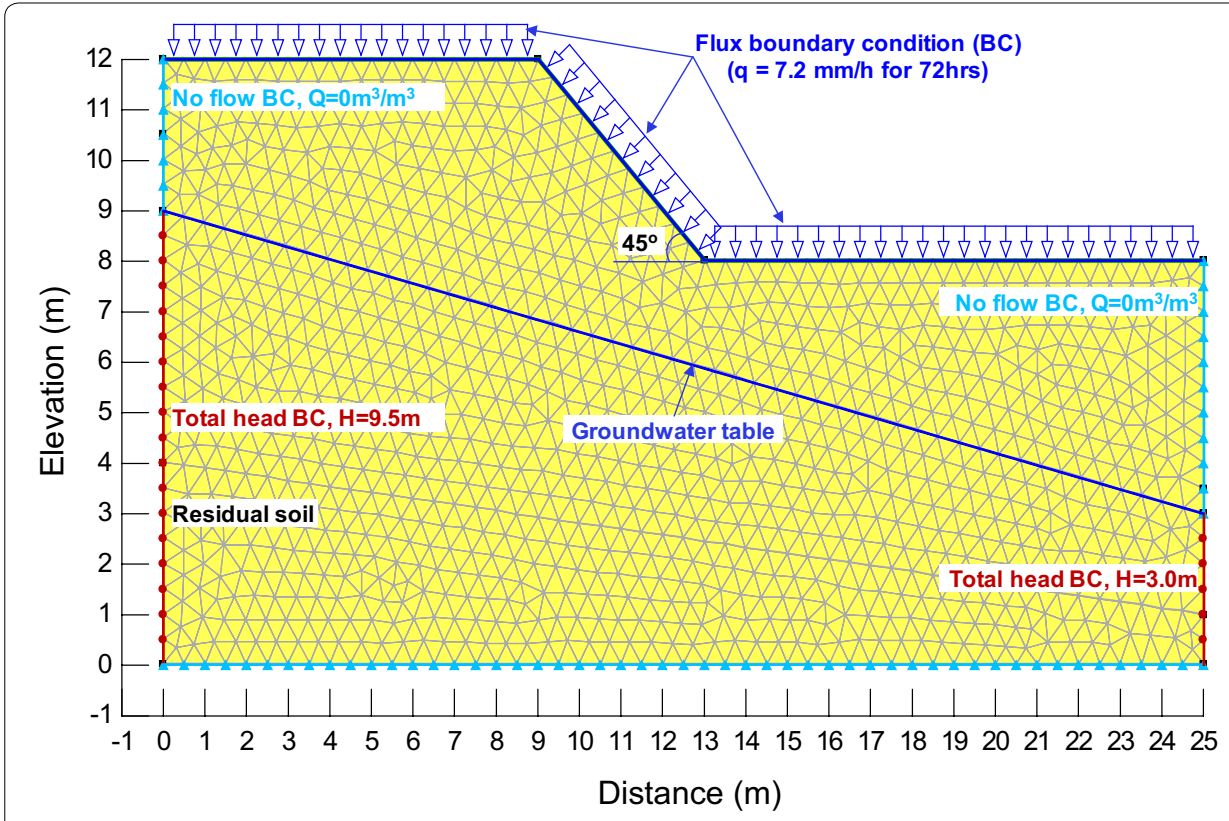

a Original slope

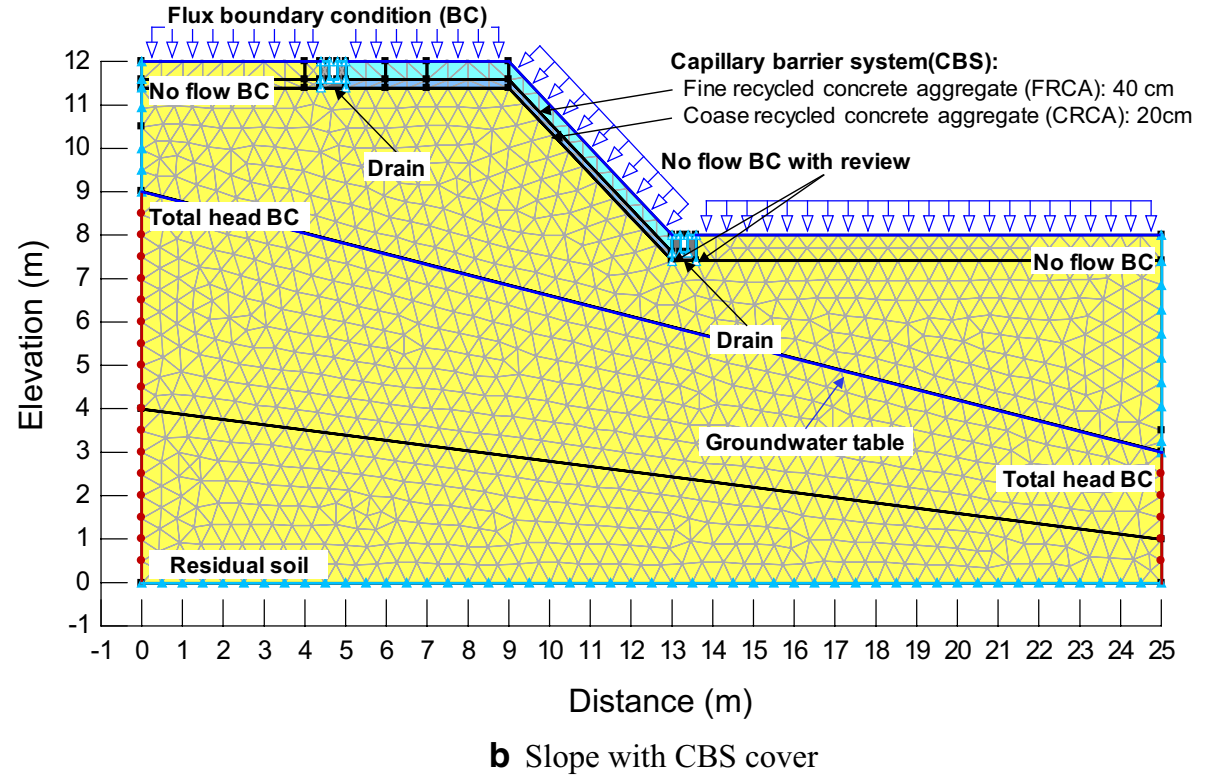

Fig. 14 Slope geometry and boundary conditions

boundary flux, $q$, equal to rainfall intensity, $I_{r}=7.2 \mathrm{~mm} / \mathrm{h}\left(2 \times 10^{-6} \mathrm{~m} / \mathrm{s}\right)$ was applied to the surface of the slope. Ponding was not allowed to occur on the ground surface, which means that the pore-water pressure on the ground surface would not be allowed to be higher than $0 \mathrm{kPa}$. The nodal flux, $Q$, equal of zero was applied along the sides of the slope above the groundwater table and along the bottom of the slope to simulate no flow zone. The nodal flux, $Q$, equal to zero with review was applied along the outer boundaries of the drain to drain out the collected water. A boundary condition equal to total head, $h_{w}$, was applied along the sides of the slope below the groundwater table. The 
negative pore-water pressure in the slope was limited to $50 \mathrm{kPa}$ to reflect the typical values measured in the field.

Second, stress-strain analyses were conducted using SIGMA/W [17] software for the load/deformation modelling of the slope. The finite element model was a two-dimensional plane strain model. The finite element mesh of the slope model in SEEP/W was imported to SIGMA/W. The pore-water pressure was computed by seepage analyses and used as initial pore-water pressure for load/deformation analyses. The fixed boundary condition of the slope model was assumed that horizontal displacement was fixed on both side boundaries and displacements in both directions were fixed on the bottom boundary of the model. The pore-water pressure distribution was selected for each time increment, and the corresponding deformation was calculated.

For stress-strain analyses, the soil particles were treated as continuum and they were modelled as an elastic-plastic constitutive model in SIGMA/W. Two stress state variables were used to model the unsaturated soil constitutive equations. The two incremental constitutive equations for unsaturated soils are written as follows:

$$
\begin{aligned}
& d \varepsilon_{i j}=\frac{1+v}{E} d \sigma_{i j}-\frac{v}{E} d \sigma_{\text {mean }} \delta_{i j}-\frac{1}{H} d u_{w} \delta_{i j} \\
& d \theta_{w}=\frac{\beta}{3} \varepsilon_{v}-\frac{1}{R} d u_{w}
\end{aligned}
$$

where $\varepsilon_{i j}$ is the strain tensor, $v$ is the Poisson's ratio, $E$ is the elastic modulus of the soil, $\sigma_{\text {mean }}$ is the mean total stress, $u_{w}$ is the pore-water pressure, $\delta_{i j}$ is the Kronecker delta, $H$ is the elasticity parameter of the soil with respect to a change in matric suction, $\beta=E / H(1-2 v), \varepsilon_{v}$ is the volumetric strain, and $R$ is the parameter relating the volumetric water content to a change in pore-water pressure. Substituting Eq. 24 into Eq. 25 yields Eq. 26, that relates the change in volumetric water content to change in volume of the soil:

$$
d \theta_{w}=\beta \varepsilon_{v}-\omega d u_{w}
$$

where $\omega=\frac{1}{R}-\frac{3 \beta}{H}$.

Third, slope stability analyses were conducted using SLOPE/W [17]. The finite element mesh and pore-water pressure distribution of the slope model in SEEP/W were imported to SLOPE/W. The typical saturated and unsaturated shear strengths for the residual soils were used in the slope stability analyses using Morgenstern-Price method. The pore-water pressure distribution was selected for each time increment and the corresponding factor of safety was calculated.

\section{Results of numerical analysis}

Figure 15 exhibits the variations in factor of safety (FS) obtained from the SLOPE/W analyses of the original slope and the slope with CBS cover. The initial FS of the slope with CBS cover was 1.64 that was slightly higher than 1.61 of the original slope due to the reinforcement of the CBS cover. The rate of decrease in FS versus time was faster for the original slope, followed by the covered slope. The FS for the original slope reached 1.0 at the end of the rainfall event while the FS for the slope with CBS cover reached 1.36 


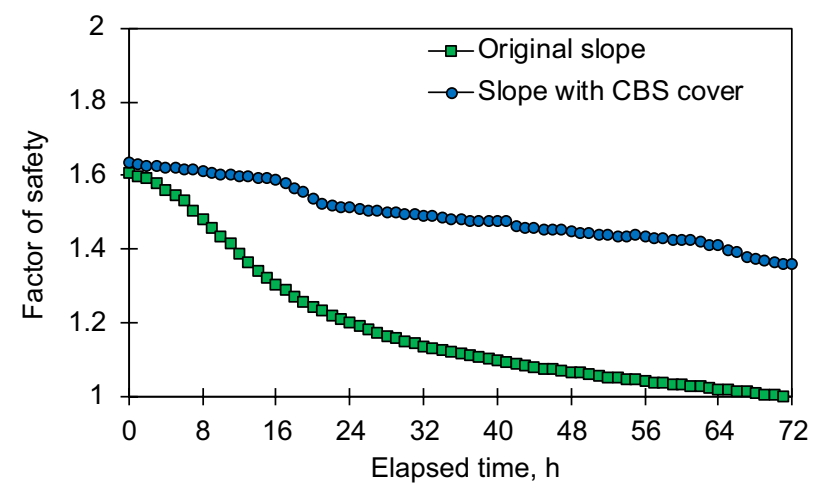

Fig. 15 Variations in factor of safety for the original slope and the slope with CBS cover
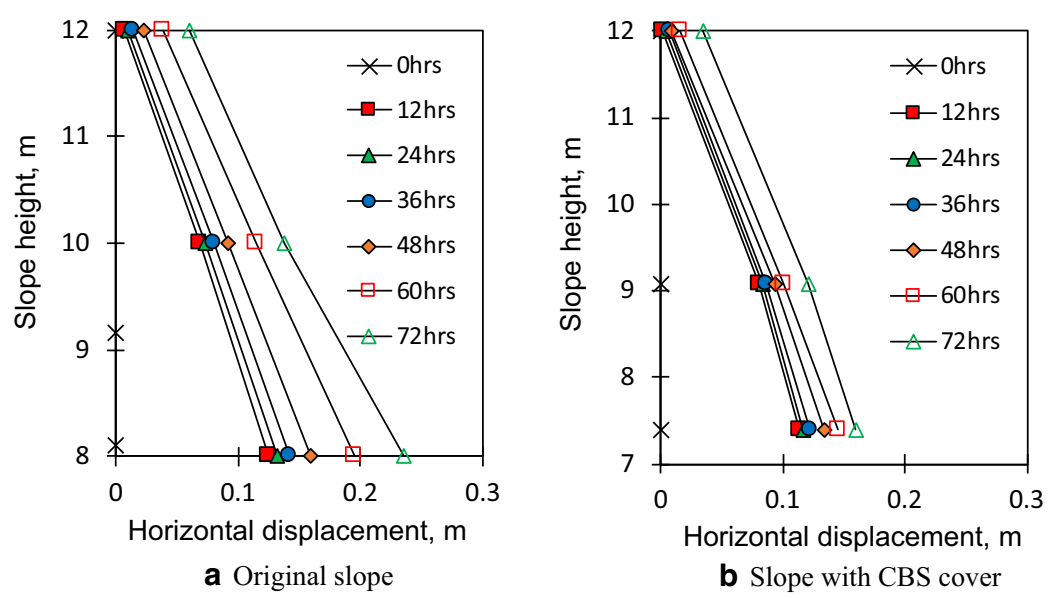

Fig. 16 Horizontal deformation of the slope with time during rainfall

at the end of the rainfall event. As expected, the CBS has a significant effect on the slope stability during the transient conditions.

Figure 16 shows the slope deformations at slope crest, slope midpoint, and slope toe along the critical slip surface whose locations are shown in Fig. 17. The critical slip surface was determined from SLOPE/W analyses. Note that the two slopes had a higher horizontal displacement during rainfall as compared to the vertical displacement of the slope. Therefore, horizontal displacements were used to calculate the dimensionless displacement. Figure 16a shows that the deformation of the original slope increased with time during rainfall, especially the rate of increase in deformation increased rapidly after $36 \mathrm{~h}$ which corresponded to failure time as shown in Fig. 18a. On the other hand, Fig. 16b shows that horizontal displacements of the slope with CBS cover exhibited a lower value than those of the original slope. In addition, the rate of increase in deformation was not significant. Consequently, there was no evidence of the inflection point on the relationship between the dimensionless displacement and time as shown in Fig. 18b.

Figure 18 shows the relationship between the dimensionless displacement and elapsed time at different locations during the rainfall. To find the failure condition, two tangent lines were drawn on each curve in Fig. 18. Figure 18a shows that the dimensionless 


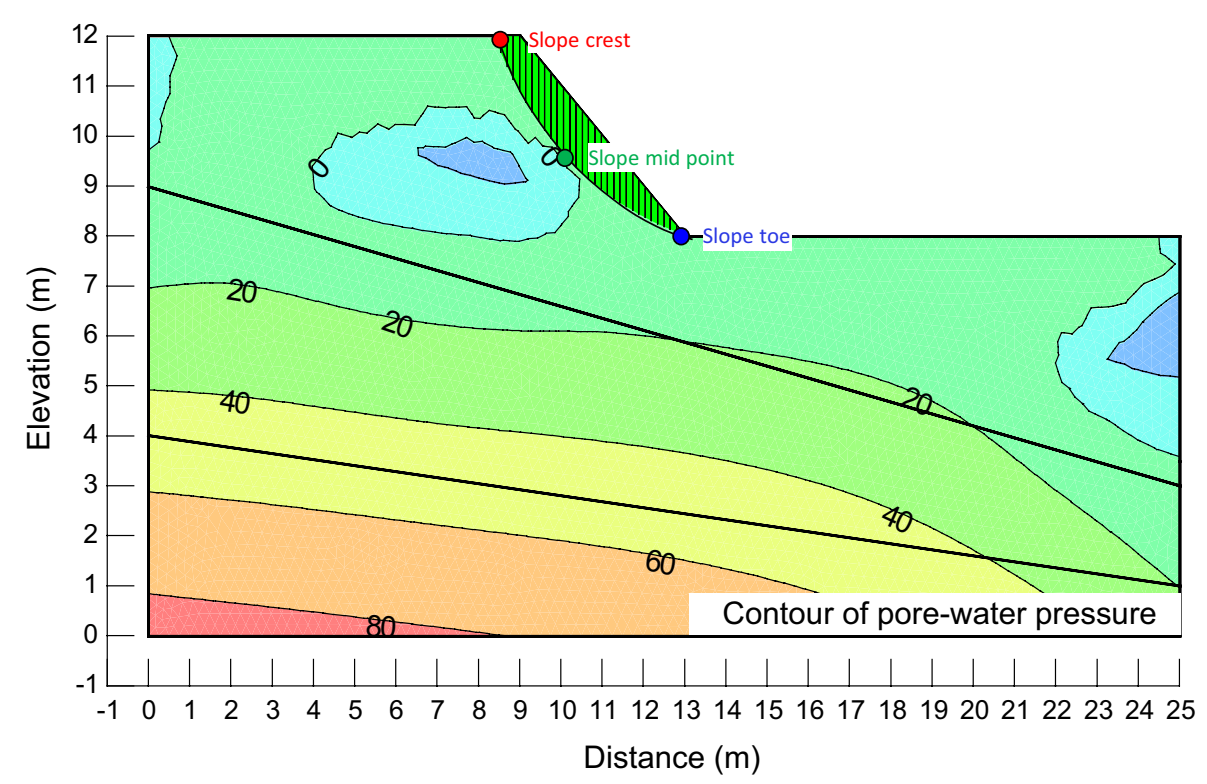

a Original slope

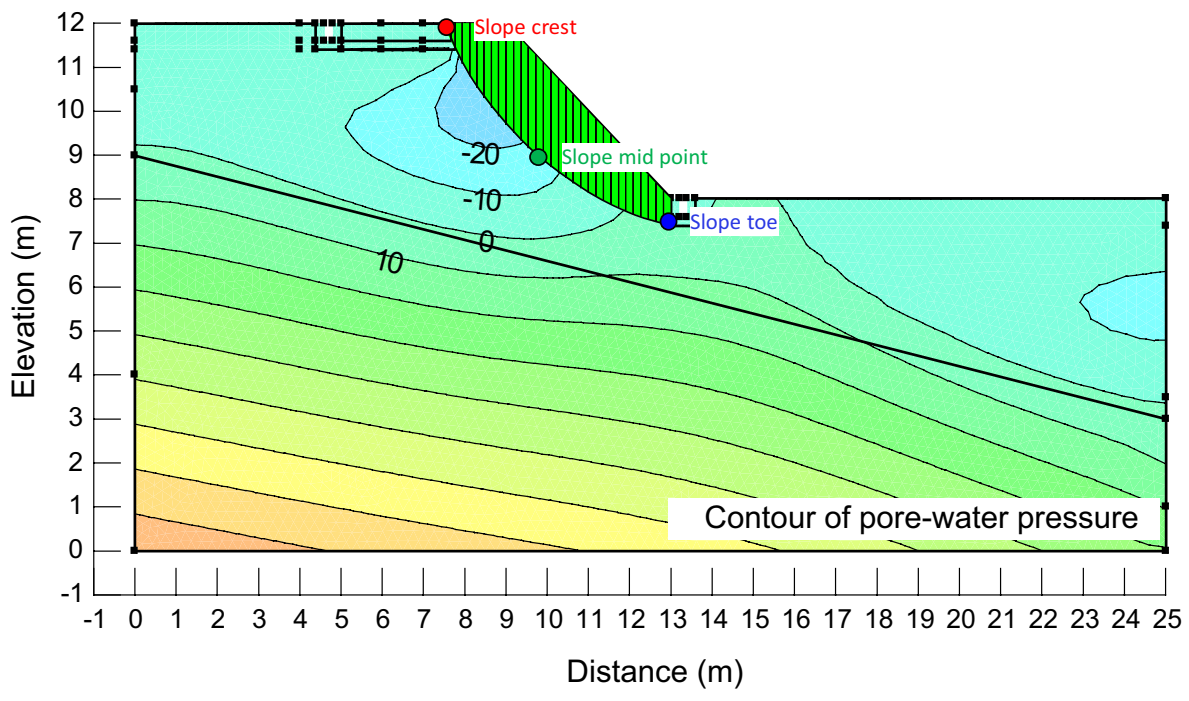

b Slope with CBS cover

Fig. 17 Distribution of pore-water pressures at the end of rainfall event, critical slip surface, and location of the observed deformations on the slopes

displacement of the original slope at three locations increased sharply after an elapsed time of $36 \mathrm{~h}$, which can be considered as a condition near instability (corresponding FS was 1.12 as indicated in Fig. 15). On the other hand, the dimensionless displacement of the slope with CBS cover at three locations increased, but the rate of increase in the dimensionless displacement was not significant to find the failure condition.

The comparison between SLOPE/W and SIGMA/W results shows that time to failure from SIGMA/W analyses tends to be earlier than that from SLOPE/W analyses. This could be due to the fact that the limit equilibrium solution provides only one average FS 

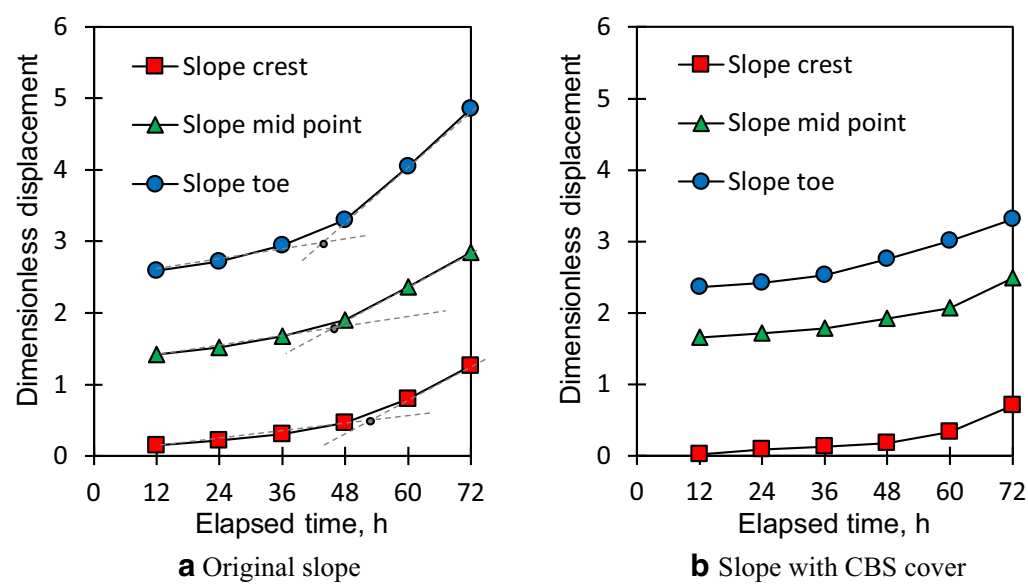

Fig. 18 Dimensionless displacement of the original slope

for the critical slip surface without considering the stress-strain distribution in the slope due to rainfall infiltration, whereas the stress-strain analyses performed in this study considers the deformation characteristics from the stress-strain distribution in the slope at several points in the slope. Therefore, the stress-strain analyses can detect progressive failure and potential failure of the slope earlier. Therefore, the design criteria [21], require a specific FS of greater than 1.0 in the design of actual soil slopes. For example, the slopes in South Korea are designed using a national code with a FS of 1.3 [30].

The comparison between the original and the slope with CBS cover in SIGMA/W shows that the volumetric water content in unsaturated soils may increase under rainfall, inducing the change in permeability function rapidly. At the same time, the alteration of the hydraulic condition, in turn, changes the water flow within the slope and may also alter volumetric response of the soil. The CBS can control the rain water infiltration into the soil slope and SIGMA/W analyses can capture the coupling processes under the transient conditions. Consequently, unsaturated soil slopes are vulnerable to lose their overall stability due to the reduction in the shear strength caused by rain infiltration.

\section{Conclusions}

The following remarks can be concluded from this paper:

1. The principles and theories of the unsaturated soil mechanics are required for describing the behaviour of natural soils which are commonly observed in unsaturated conditions.

2. Apparatuses, procedures and methodologies for unsaturated soil testing are available for characterization of unsaturated soil properties.

3. Assessment of environmental changes on geotechnical structures such as slopes should incorporate the mechanics and properties of unsaturated soils in the numerical analyses.

4. The capillary barrier system using the principles of unsaturated soil mechanics has been shown to be effective in minimizing rainwater infiltration into slopes and preventing slope failures. 


\section{Recommendations}

Unsaturated soil mechanics principles are also important in designing other slope preventive measures, such as: horizontal drains and vegetative cover. Future studies can be carried out to investigate the optimum design of horizontal drains in maintaining the positions of groundwater table during dry and rainy periods within different type of soil slopes. In addition, future research works can be carried out to study the best type of vegetations that are effective in preventing the rainfall-induced slope failures.

\section{Acknowledgements}

The work described in this paper is supported by the Housing and Development Board (HDB) and Nanyang Technological University, Singapore. The Authors acknowledge gratefully the research funding provided by Building and Construction Authority (BCA), Singapore for this presentation.

\section{Authors' contributions}

HR designed the study, YK carried out the numerical simulations and participated in the result analysis, AS conducted the laboratory experiments and prepared for the manuscript. All authors read and approved the final manuscript.

\section{Competing interests}

The authors declare that they have no competing interests.

Received: 6 March 2019 Accepted: 5 June 2019

Published online: 13 June 2019

\section{References}

1. ASTM D2487-11 (2011) Standard practice for classification of soils for engineering purposes (unified soil classification system). Annual Book of ASTM Standards. ASTM International, West Conshohocken

2. ASTM D6838-02 (2008) Standard test methods for the soil-water characteristic curve for desorption using hanging column, pressure extractor, chilled mirror hygrometer, or centrifuge. Annual Book of ASTM Standards. ASTM International, West Conshohocken

3. ASTM D 422 (1998) Standard test method for particle-size analysis of soils. Annual Book of ASTM Standards. ASTM International, West Conshohocken

4. Aung KK, Rahardjo H, Leong EC, Toll DG (2001) Relationship between porosimetry measurement and soil-water characteristic curve for an unsaturated residual soil. Geotech Geol Eng 19:401-416

5. Brooks RH, Corey AT (1966) Properties of porous media affecting fluid flow. J Irrig Drain Div ASCE 92(2):61-68

6. Chen H, Dadson S, Chi YG (2006) Recent rainfall-induced landslides and debris flow in northern Taiwan. Geomorphology 77:112-125

7. Childs EC, Collis-George N (1950) The permeability of porous materials. Proc R Soc A Math Phys Eng Sc 201(1066):392-405

8. Ciabatta L, Camici S, Brocca L, Ponziani F, Stelluti M, Berni N, Moramarco T (2016) Assessing the impact of climatechange scenarios on landslide occurrence in Umbria Region, Italy. J Hydrol 541(A):285-295

9. Doran PT, Zimmerman MK (2009) Examining the scientific consensus on climate change. EOS T Am Geophys Un 90(3):22-23

10. Fredlund DG (2006) Unsaturated soil mechanics in engineering practice. J Geotech Geoenviron 132(3):286-321

11. Fredlund DG, Morgenstern NR (1977) Stress state variables for unsaturated soils. J Geotech Eng 103:447-466

12. Fredlund DG, Morgenstern NR, Widger RA (1978) Shear strength of unsaturated soils. Can Geotech J 15(3):313-321

13. Fredlund DG, Rahardjo H (1993) Soil mechanics for unsaturated soils. Wiley, New York

14. Fredlund DG, Rahardjo H, Fredlund MD (2012) Unsaturated soil mechanics in engineering practice. Wiley, New York

15. Fredlund DG, Xing A (1994) Equations for the soil-water characteristic curve. Can Geotech J 31(3):521-532

16. Fredlund MD, Wilson GW, Fredlund DG (2002) Representation and estimation of the shrinkage curve. In: Proceedings of the third international conference on unsaturated soils, Brazil, March 10-13, pp 145-149

17. GEOSTUDIO User's Manual (2012) Geo-slope international Ltd. Calgary, Alberta

18. Goh SG, Rahardjo H, Leong EC (2010) Shear strength equations for unsaturated soil under drying and wetting. J Geotech Geoenviron 136(4):594-606

19. Han KK (1997) Effect of hysteresis, infiltration and tensile stress on the strength of an unsaturated soil. PhD Thesis. Nanyang Technological University Singapore

20. Hilf JW (1956) An investigation of pore water pressure in compacted cohesive soils

21. Housing and Development Board (HDB) (2012) HDB design, building \& quality requirements for A\&A work on HDB premises. Housing and Development Board, Singapore

22. Jeong S, Kim Y, Lee JK, Kim J (2015) The 27 July 2011 debris flows at Umyeonsan, Seoul, Koreall. Landslides 12(4):799-813

23. Jeong S, Lee K, Kim J, Kim Y (2017) Analysis of rainfall-induced landslide on unsaturated soil slopes. Sustainability $9(7): 1280-1299$

24. Kim J, Jeong S, Regueiro RA (2012) Instability of partially saturated soil slopes due to alteration of rainfall pattern. Eng Geol 147:28-36

25. Kim J, Hwang W, Kim Y (2018) Effects of hysteresis on hydro-mechanical behavior of unsaturated soil. Eng Geol 245:1-9 
26. Kim Y, Jeong S, Kim J (2016) Coupled infiltration model of unsaturated porous media for steady rainfall. Soils Found 56(6):1073-1083

27. Kim Y, Lee S, Jeong S, Kim J (2013) The effect of pressure-grouted soil nails on the stability of weathered soil slopes. Comp Geotech 49:253-263

28. Kim Y, Jeong S (2017) Modeling of shallow landslides in an unsaturated soil slope using a coupled model. Geomech Eng 13(2):353-370

29. Kim Y, Rahardjo H, Satyanaga A (2017) Numerical simulations of triaxial shearing-infiltration tests. Soils Found 58(2):398-411

30. Korea Infrastructure Safety Corporation (2011) Design criteria for constructed slopes. Korea

31. Krisdani H, Rahardjo H, Leong EC (2009) Use of instantaneous profile and statistical methods to determine permeability functions of unsaturated soils. Can Geotech J 46(7):869-874

32. Kunze RJ, Uehara G, Graham K (1968) Factors important in the calculation of hydraulic conductivity. Proc Soil Sci Soc Am 32:760-765

33. Leong EC, Rahardjo H (1997) Review of soil-water characteristic curve equations. J Geotech Geoenviron 123(12):1106-1117

34. Leong EC, Rahardjo H (1997) Permeability function for unsaturated soils. J Geotech Geoenviron 123(12):1118-1126

35. Matyas EL, Radhakrishna HS (1968) Volume change characteristics of partially saturated soils. Geotechnique 18(4):432-448

36. Mualem Y (1976) A new model for predicting the hydraulic conductivity of unsaturated porous media. Water Resour Res 12:513-522

37. O'Hare G, Sweeney J, Wilby R (2005) Weather, climate and climate change: human perspectives. Taylor \& Francis, New York

38. Park BS, Cho H, Youn SP (2016) Analysis and evaluation of stability for the reactivated landslide along deep-seated weakness zones. Int J Geo Eng 7:3

39. Rahardjo H, Kim Y, Gofar N, Leong EC, Wang CL, Wong JLH (2018) Field instrumentations and monitoring of GeoBarrier System for steep slope protection. Trans Geotech 16:29-42

40. Rahardjo H, Krisdani H, Leong EC (2007) Application of unsaturated soil mechanics in capillary barrier system, invited lecture. In: Proceedings of 3rd asian conference on unsaturated soils, Nanjing, China, pp 127-137

41. Rahardjo H, Li XW, Toll DG, Leong EC (2001) The effect of antecedent rainfall on slope stability. J Geotech Geol Eng 19(3-4):371-399

42. Rahardjo H, Lim TT, Chang MF, Fredlund DG (1995) Shear strength characteristics of a residual soil in Singapore. Can Geotech J 32:60-77

43. Rahardjo H, Meilani I, Leong EC (2009) Shear strength characteristics of a compacted soil under infiltration conditions. Geomech Eng 1(1):35-52

44. Rahardjo H, Satyanaga A, Leong EC (2013) Effects of flux boundary conditions on pore-water pressure distribution in slope. Eng Geol 165:133-142

45. Rahardjo H, Satyanaga A, Leong EC, Ng YS (2010) Effects of groundwater table position and soil properties on stability of slope during rainfall. J Geotech Geoenviron 136(11):1555-1564

46. Rahardjo H, Satyanaga A, Leong EC, Wang JY (2014) Comprehensive instrumentation for real time monitoring of flux boundary conditions in slope. Proced Earth Plan Sc 9:23-43

47. Rahardjo H, Satyanaga A, Mohamed H, Ip CY, Rishi SS (2018) Comparison of soil-water characteristic curves from conventional testing and combination of small-scale centrifuge and dew point methods. J Geotech Geol Eng (in Press)

48. Rahardjo H, Tami D, Leong EC (2006) Effectiveness of Sloping Capillary Barriers Under High Precipitation Rates. Proceedings of 2nd International Conference on Problematic Soils, Petaling Jaya, Selangor, Malaysia, 3-5 December, pp 39-54

49. Rahardjo H, Vilayvong K, Leong EC (2010) Water characteristic curves of recycled materials. Geotech Test J 34(1):1-8

50. Schindler U, Müller L (2006) Simplifying the evaporation method for quantifying soil hydraulic properties. J Plant Nutri Soil Sc 169:623-629

51. Strauch AM, Mackenzie RA, Giardina CP, Bruland GL (2017) Climate driven changes to rainfall and streamflow patterns in a model tropical island hydrological system. J Hydrol 523:160-169

52. Tami D, Rahardjo H, Leong EC (2007) Characteristics of Scanning Curves of Two Soils. Soils Found 47(1):97-109

53. Terzaghi K (1943) Theoretical soil mechanics. Wiley, New York

54. Toll DG, Rahardjo H, Leong EC (1999) Landslides in Singapore. In: Proc 2nd international conference on landslides, slope stability and the safety of infra structure, Singapore, pp 269-276

55. Wijaya M, Leong EC (2016) Performance of high-capacity tensiometer in constant water content oedometer test. Int J Geo Eng 7:13

56. Wong JC, Rahardjo H, Toll DG, Leong EC (2001) Modified triaxial apparatus for shearing-infiltration test. Geotech Test J 24(4):370-380

57. Zhai Q, Rahardjo H (2015) Estimation of permeability function from the soil-water characteristic curve. Eng Geol 199:148-156

58. Zienkiewicz OC, Taylor RL, Nithiarasu P (2005) The finite element method, 6th edn. Butterworth-Heinemann, Oxford

\section{Publisher's Note}

Springer Nature remains neutral with regard to jurisdictional claims in published maps and institutional affiliations. 